\title{
Biofilm Formation by Filamentous Fungi Recovered from a Water System
}

\author{
Virgínia M. Siqueira and Nelson Lima \\ Institute for Biotechnology and Bioengineering, Centre of Biological Engineering, University of Minho, Campus de Gualtar, \\ (IBB), 4710-057 Braga, Portugal
}

Correspondence should be addressed to Virgínia M. Siqueira; virginiamedeiros@hotmail.com

Received 8 December 2012; Revised 10 February 2013; Accepted 16 February 2013

Academic Editor: Praveen Rao Juvvadi

Copyright (C) 2013 V. M. Siqueira and N. Lima. This is an open access article distributed under the Creative Commons Attribution License, which permits unrestricted use, distribution, and reproduction in any medium, provided the original work is properly cited.

\begin{abstract}
Filamentous fungi have been constantly recovered from diverse aquatic environments including drinking water distribution systems. Although most of the works are focused on the study of planktonic form, recent researches have shown that fungi develop biofilm within these systems. In this study, Aspergillus sp. (section Nigri), Aspergillus sp. (section Flavi), Alternaria sp., Botrytis sp., Cladosporium sp., and Penicillium sp. recovered from water biofilms were used to evaluate their capability to grow as biofilms under laboratorial conditions. Morphological and physiological characteristics were analysed using image analysis and biomass and cell activity estimation. All six isolates were able to form biofilm, though different patterns of development were observed. Only Alternaria sp. formed biofilm in water over $24 \mathrm{~h}$ of analysis. MEB was shown to be the best culture media for biofilm formation. A direct correlation between biomass and cell activity was not observed, but biomass values and morphological parameters, that is, monolayer and EPS production, were directly correlated. Thus, the results present here highlight the capability of fungi to form biofilms and the emergent necessity to standardize methods for further research in this area.
\end{abstract}

\section{Introduction}

Filamentous fungi (ff) have been frequently isolated from aquatic environments such as rivers, streams, lakes, and sea [1]. Water distribution systems (WDS) are nowadays seen as complex aquatic environments in which high diverse microorganisms cohabit, including fungi [2]. Regardless of their importance for human health, little is known about microbial ecology of ff within WDS. Moreover, the focuses of microbial water quality studies still remain on monitoring planktonic microorganisms, despite scientists' awareness that the majority of microorganisms live together as biofilms [3].

Due to its important role in the environment, industry, and medicine, the understanding of mechanisms of biofilm formation has become the focus of biofilm research. Research in ff biofilm in WDS has only recently received attention [4-6]. Most of previous mycological studies are focused on pathogenic fungi, for example, Candida spp. [7-9], Aspergillus fumigatus [10-12], and opportunistic zygomycetes [13]. Increased resistance against antimicrobials is a well-known and still worrying clinical relevant biofilm feature, and wherefore these studies have especially established suitable methods for antimicrobial biofilm susceptibility assay [14-16]. Ramage et al. [17] reported the importance of fungal biofilm phenotype concept in medical and industrial mycological research. These authors described schematically Aspergillus biofilms development and discussed morphological, physiological, and molecular features related to both fungal virulence and enzymatic production.

Studies have reported the detection of ff within biofilms in different habitats such as rocks [18], fuel tanks [19], historic monuments [20-22], acid mine drainage [23], and pipe walls [24]. Nonetheless, the improvement and standardisation of suitable methods for laboratorial studies of ff biofilms are still needed. Characterisation of the development, physiology, architecture, disinfectant resistance, and factors that influence genetic and phenotypic expression of ff biofilms is still unknown for most ff species, even for those frequently recovered from WDS. Additionally, it is important to highlight that $\mathrm{ff}$ are eukaryotic organisms which have 
peculiar characteristics, for example, nutrition by absorption, development of reproductive and vegetative structures (i.e., spore and hyphae), and sexual and asexual reproduction, hence when compared with bacterial and yeast biofilms, different approaches must be employed.

Thus, this work aims to investigate the capability of biofilm formation, and their morphological and physiological characterisation, of fungi isolated from biofilms in a water system.

\section{Material and Methods}

2.1. Fungal Isolates. Aspergillus sp. 1 (section Nigri), Aspergillus sp. 2 (section Flavi), Alternaria sp., Botrytis sp., Cladosporium sp., and Penicillium sp. were used in this study. These strains were recovered from biofilms developed in a flow chamber reactor setup at the Laboratory of Mycology of the Biological Engineering Centre, University of Minho, Braga, Portugal, during a previous study [25]. The fungi were maintained in MEA (malt extract $20 \mathrm{~g}$, peptone $5 \mathrm{~g}$, agar $20 \mathrm{~g}$, distilled water $1 \mathrm{~L}$ ) at $25^{\circ} \mathrm{C}$.

2.2. Biofilm Formation. Spores of each isolate were harvested from 7 days aged pure culture in MEA by adding $2 \mathrm{~mL}$ of saline solution $(0.85 \%)$ into plate. The spore suspension was resuspended and vortexed before quantification. The suspensions were standardized by dilution with saline solution $(0.85 \%)$ to a final concentration of $10^{5}$ spores $/ \mathrm{mL}$ and using a Neubauer counter chamber.

For biofilm kinetics, $100 \mu \mathrm{L}$ of spore suspension and $100 \mu \mathrm{L}$ of culture broth media MEB (malt extract $20 \mathrm{~g}$, peptone $5 \mathrm{~g}$, distilled water $1 \mathrm{~L}$ ), R2A broth (proteose peptone $0.5 \mathrm{~g}$; casamino acids $0.5 \mathrm{~g}$; yeast extract $0.5 \mathrm{~g}$; dextrose $0.5 \mathrm{~g}$; soluble starch $0.5 \mathrm{~g}$; dipotassium phosphate $0.3 \mathrm{~g}$, magnesium sulphate $7 \mathrm{H}_{2} \mathrm{O} 0.05 \mathrm{~g}$; sodium pyruvate $0.3 \mathrm{~g}$; distilled water $1 \mathrm{~L} ; \mathrm{pH} 7.2$ ), and $100 \mu \mathrm{L}$ of sterilised tap water were added per well into 96-well, flat-bottomed polystyrene microtiter plates. Media-only blanks were also set up. The plates were incubated at $30^{\circ} \mathrm{C}$ for $24 \mathrm{~h}$ and analyses were made at $4,8,12$, and $24 \mathrm{~h}$. Time of analysis was chosen based on a protocol for filamentous fungal biofilm in 96-well plates described by [26]. Biofilm visualization and EPS detection were performed using a stereomicroscope (Leica; DFC450 Camera with Leica Application Suite software) and morphological and structural parameters analysis were followed as described by [27].

\subsection{Biofilm Kinetics}

2.3.1. Biofilm Quantification. Biofilm biomass was assessed using a protocol described elsewhere [24]. Briefly, at each time interval (i.e., 4, 8, 12, and $24 \mathrm{~h}$ ), the spent culture medium was removed from each well and the adherent cells were washed with phosphate-buffered saline (PBS; 0.1 M, pH 7.2). These were airdried and $200 \mu \mathrm{L}$ of $0.5 \%$ (w/v) crystal violet (CV) solution was added for $30 \mathrm{~min}$. The solution was then removed until excess stain was removed. The biofilms were distained by adding $200 \mu \mathrm{L} 95 \%$ ethanol to each well. The ethanol was gently pipetted to completely solubilize the CV for $1 \mathrm{~min}$, the ethanol was transferred to a clean 96-well microtitre plate, and the $\mathrm{OD}_{570}$ was read using a microtiter plate reader (Model Synergy HT; BIO-TEK). The OD values are proportional to the quantity of biofilm biomass, which comprises hyphae and extracellular polymeric material (the greater the quantity of biological material, the higher the level of staining and absorbance).

2.3.2. MTT Assay. MTT (3-(4,5-dimethyl-2-thiazolyl)-2,5diphenyl-2H-tetrazolium bromide) is a yellow soluble tetrazolium salt that is converted into an insoluble purple crystal by metabolically active cells. MTT (Sigma) solution was aseptically prepared by dissolving the MTT powder at a concentration of $5 \mathrm{mg} / \mathrm{mL}$ in sterile PBS at room temperature and stored at $4^{\circ} \mathrm{C}$ in a dark, screw-cap container. At each time point, $0.2 \mathrm{~mL}$ of MTT solution were added to each well and the 96-well plates were incubated at $37^{\circ} \mathrm{C}$ during $3 \mathrm{~h}$. After this period, the supernatant was then discarded and $0.2 \mathrm{~mL}$ dimethyl sulfoxide (DMSO) was added to each well to solubilize the MTT, which had been cleaved into an insoluble purple formazan through the metabolism of the live cells. Biofilm development was assayed by loading $0.2 \mathrm{~mL}$ of the solubilized MTT into a flat-bottom, 96-well polyvinyl chloride microtiter plate, and absorbance measured at $\mathrm{OD}_{570} \mathrm{~nm}$ using a microtiter plate reader (Model Synergy HT; BIOTEK).

\section{Results}

Biofilm formation by Aspergillus sp. 1, Aspergillus sp. 2, Botrytis sp., Alternaria sp., Cladosporium sp., and Penicillium sp. grown in different culture media over $24 \mathrm{~h}$ was characterised, as revealed by both crystal violet $(\mathrm{CV})$ biomass estimation and the colorimetric MTT assay. Figure 1 shows the mean value of absorbance level for CV staining (total biofilm), and Figure 2 shows the mean value of absorbance level for MTT staining (viable cells). Additionally, image analysis was used to assess morphological aspects of biofilm formation (Figures $3-8)$.

A direct relation was observed between biomass (CV), and biofilm development (Figures 1 and 3-8). On the other hand, a direct relation between biomass (CV) and metabolic active cells (MTT) was not observed (Figures 1 and 2).

In water, biofilms showed a higher cell activity in the first $4 \mathrm{~h}$ of analyses (MTT), and lower along time (Figure 2(a)). In adverse conditions, spores may enter in a dormancy status with lower cells metabolic activity. In R2A and MEB, biomass and cell activity showed higher values along time. Different patterns of biofilm development were observed between the culture media and fungi. The time when adherence of spores, monolayer development, and EPS production were observed for each fungus biofilm is described in Table 1.

Alternaria sp. and Botrytis sp. were the fungi that formed biofilm in water and Penicillium sp. showed spore adherence after 24 h under this same condition (Figures 3 and 4). In R2A, biofilms were formed mainly after $12 \mathrm{~h}$ and EPS production was observed in both Aspergillus spp., Alternaria sp., and Botrytis sp. biofilms at $24 \mathrm{~h}$ (Figures 5 and 6). In MEB, after 
TABLE 1: Time of detection of spore adherence, monolayer, and EPS production in fungal biofilms grown in different culture media.

\begin{tabular}{|c|c|c|c|c|c|c|c|c|c|}
\hline \multirow{2}{*}{ Fungus } & \multicolumn{3}{|c|}{ Water } & \multicolumn{3}{|c|}{$\mathrm{R} 2 \mathrm{~A}$} & \multicolumn{3}{|c|}{ MEB } \\
\hline & Ad & $\mathrm{Mn}$ & EPS & Ad & $\mathrm{Mn}$ & EPS & Ad & $\mathrm{Mn}$ & EPS \\
\hline Aspergillus sp. 1 & - & - & - & $4 \mathrm{~h}$ & $8 \mathrm{~h}$ & $24 \mathrm{~h}$ & $<4 \mathrm{~h}$ & $4 \mathrm{~h}$ & $8 \mathrm{~h}$ \\
\hline Aspergillus sp. 2 & - & - & - & $4 \mathrm{~h}$ & $8 \mathrm{~h}$ & $24 \mathrm{~h}$ & $<4 \mathrm{~h}$ & $4 \mathrm{~h}$ & $8 \mathrm{~h}$ \\
\hline Alternaria sp. & $4 \mathrm{~h}$ & $8 \mathrm{~h}$ & $24 \mathrm{~h}$ & $4 \mathrm{~h}$ & $8 \mathrm{~h}$ & $24 \mathrm{~h}$ & $<4 \mathrm{~h}$ & $4 \mathrm{~h}$ & $8 \mathrm{~h}$ \\
\hline Botrytis sp. & - & $24 \mathrm{~h}$ & - & $4 \mathrm{~h}$ & $8 \mathrm{~h}$ & $24 \mathrm{~h}$ & $<4 \mathrm{~h}$ & $4 \mathrm{~h}$ & $8 \mathrm{~h}$ \\
\hline Cladosporium sp. & - & - & - & $8 \mathrm{~h}$ & $24 \mathrm{~h}$ & ${ }^{*}$ & $4 \mathrm{~h}$ & $8 \mathrm{~h}$ & $12 \mathrm{~h}$ \\
\hline Penicillium sp. & $24 \mathrm{~h}$ & - & 一 & $8 \mathrm{~h}$ & $24 \mathrm{~h}$ & $*$ & $<4 \mathrm{~h}$ & $4 \mathrm{~h}$ & $8 \mathrm{~h}$ \\
\hline
\end{tabular}

Ad: adherence; Mn: monolayer; EPS: extracellular polymeric substances; -: no biofilm formation; ${ }^{*}$ not detected.

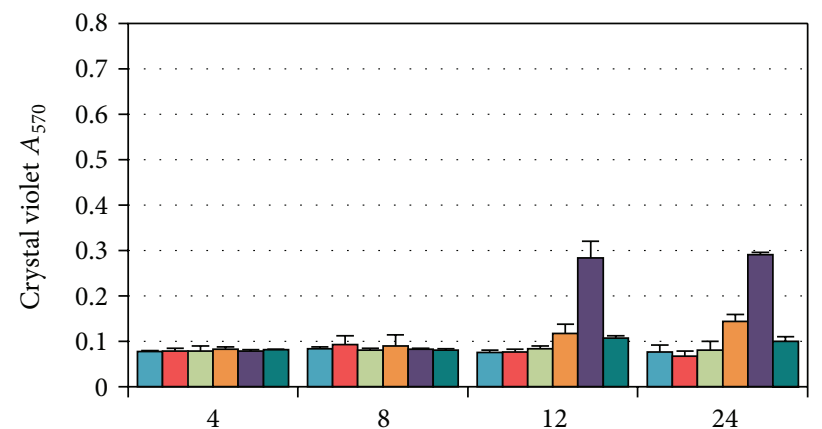

(h)

(a)

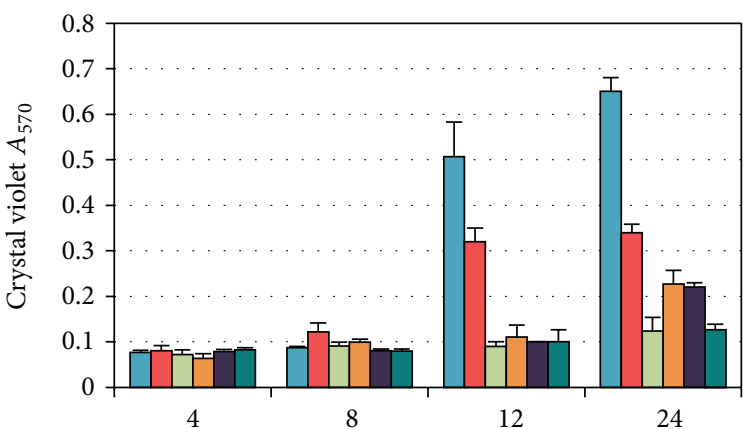

(h)

(b)

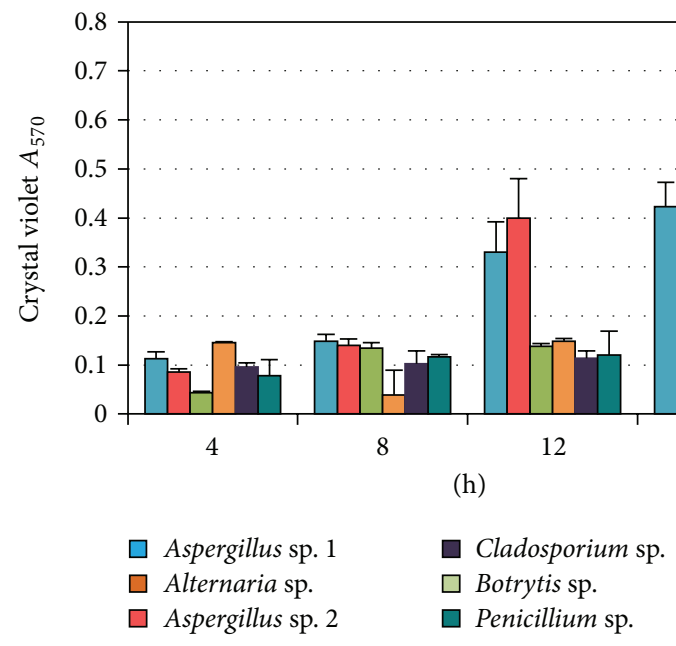

(c)

Figure 1: Total biomass (CV) in filamentous fungal biofilm grown in different culture media: (a) water, (b) R2A, and (c) MEB. The means \pm standard deviations for at least three replicates are illustrated.

$8 \mathrm{~h}$, the fungi formed mature biofilm (Figures 7 and 8), with the exception of Cladosporium sp. that showed mature biofilm in MEB after $12 \mathrm{~h}$. MEB was shown to be the best culture medium for biofilm formation, that is, in which biofilm grew faster and showed a very well-structured shape.

\section{Discussion}

The biofilm formation pattern observed in this work resembled the kinetics of biofilm formation of Aspergillus fumigatus recently proposed by Ramage et al. [17].
Previously, Harding et al. 2009 [28] proposed a model for ff biofilms which includes five stages (i) propagule adsorption, (ii) active attachment to a surface, (iii) microcolony formation I, (iv) microcolony formation II, (v) maturation or reproductive development, and (vi) dispersal or planktonic phase.

In this work, reproductive development was not observed, for example, production of conidiophores and spores over $24 \mathrm{~h}$ of growth. However, the dispersal phase can be represented by hyphal fragments which also act as dispersal propagules. Because this model has been described based on 


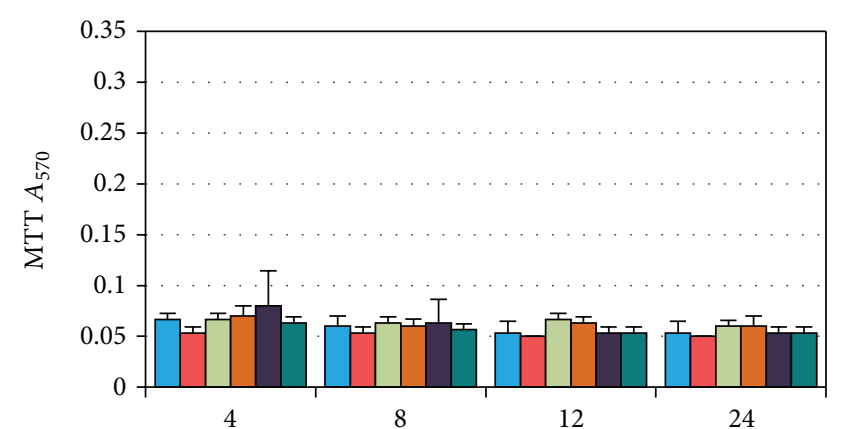

(h)

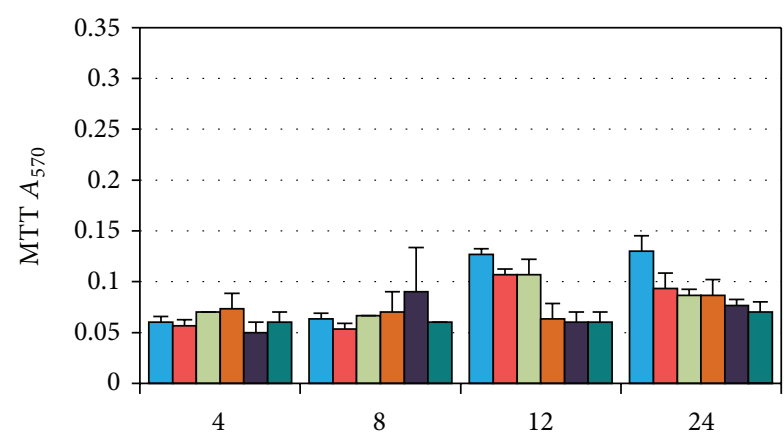

(h)

(a)

(b)

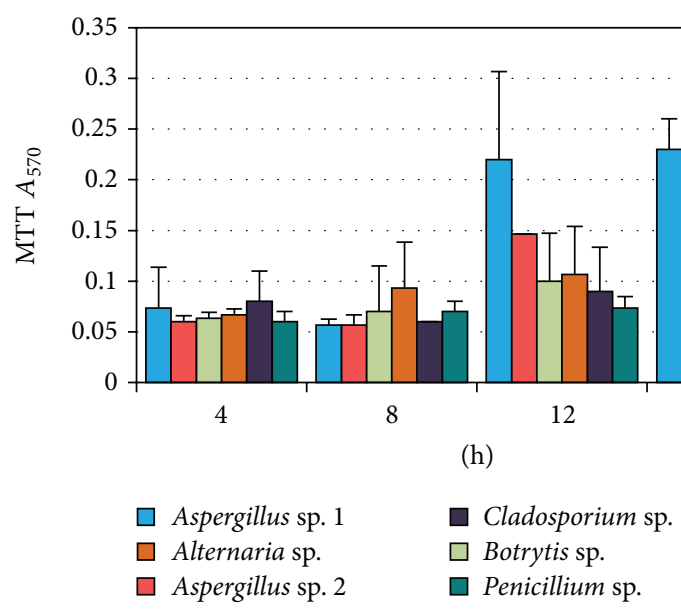

(c)

FIgURE 2: Total viable cells (MTT) in filamentous fungal biofilm grown in different culture media: (a) water, (b) R2A, and (c) MEB. The means \pm standard deviations for at least three replicates are illustrated.

bacterial and yeast models, it is important to highlight that unique features related to fungal biology distinguish bacterial from fungal biofilm formation: fungi commonly have more than one planktonic form (i.e., sexual and asexual spores, sporangia, and hyphal fragments), and these dispersive forms are not unicellular and often float in water and air as well, and the development of specialised reproductive tissues to produce dispersive forms [28]. Moreover, hyphae growth is characterised by two or three dimensions which is achieved by branching. Branch formation provides a greater regulation growth while bacterial unicellular growth is characterised by colonies which are formed by cells pilling and pushing each other apart [29]. Bacterial and yeast biofilms have been greatly studied in the last twenty years. Consequently, there are well-defined models, criteria, and phenotypes for characterizing bacterial and yeast biofilms. Differently, only in the last few years filamentous fungi had been considered as biofilm-forming microorganisms as bacteria and yeasts, even though many industrial processes and research were actually cell surface adhesion processes (e.g., solid-state fermentation) [30].

Thus, studies in $\mathrm{ff}$ biofilm must take in consideration these specific fungal features which leads to a specific way of how biofilm analyses should be carried on. Typical ff biofilm morphology is described as a complex 3D structure with cells usually enclosed within an extracellular matrix consisting of polymeric substances (EPS) [31].

Mainly after $12 \mathrm{~h}$ of biofilm growth, a layer of substances was observed surrounding fungal responsible for binding cells and other particulate materials together (cohesion) and to the surface (adhesion), that is, providing the structural support for the biofilm maturation [32]. Further studies in the characterisation of biofilm matrix may provide information about its importance in the biofilm maintenance under adverse conditions such as low nutrient levels and presence of disinfectants in WDS, and its influence in microbial interactions as well. Similar structural characteristics were found in Candida sp. and Aspergillus sp. biofilms, that is, interstitial voids and water channels with cells usually encapsulated within an extracellular matrix which may relate to their pathogenicity $[33,34]$.

The two isolates of Aspergillus sp. used in this work showed a better capacity in terms of higher biomass and cell metabolism to form biofilm when compared to the other fungal isolates. However, only Alternaria sp. was able to form biofilm in water that may represent a high adaptation to form biofilm under oligotrophic conditions. The genus Alternaria is frequently recovered from WDS ant it is known to provoke 


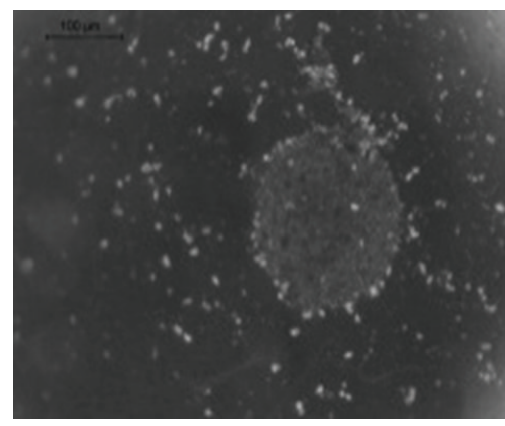

(a)

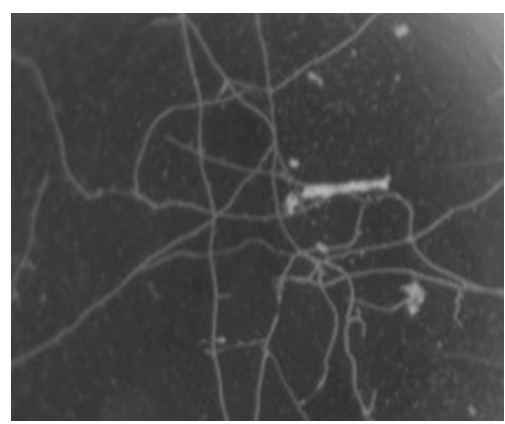

(d)

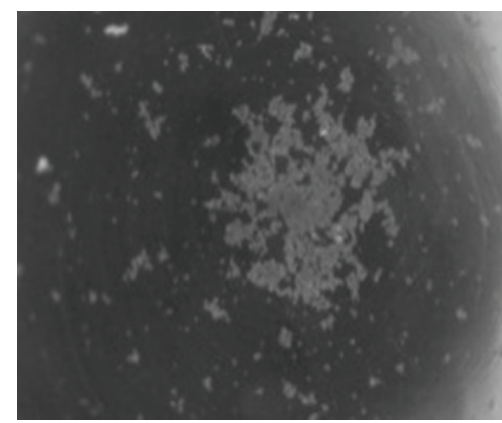

(b)

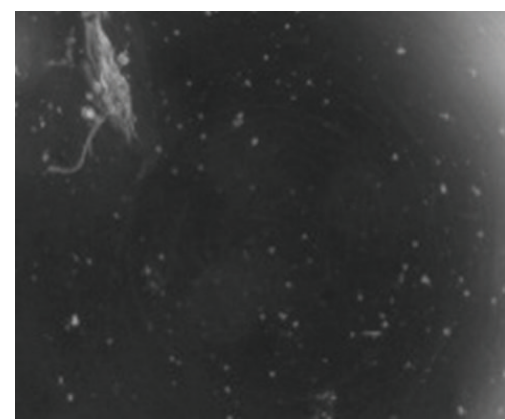

(e)

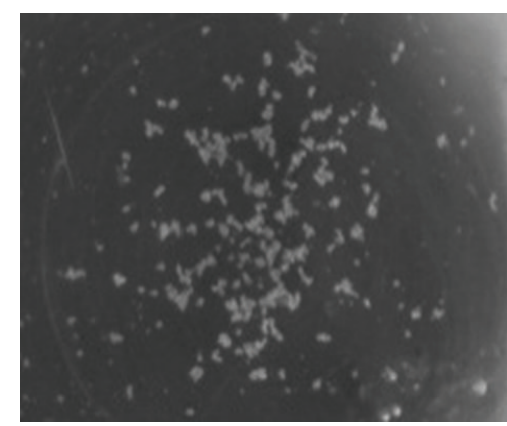

(c)

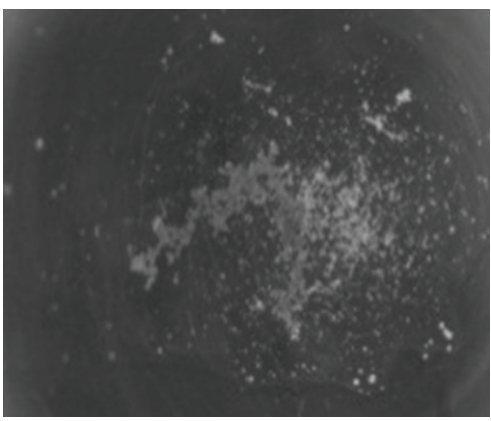

(f)

Figure 3: Aspergillus sp. 1 (a), Aspergillus sp. 2 (b), Botrytis sp. (c), Alternaria sp. (d), Cladosporium sp. (e), and Penicillium sp. (f) after 8 h in water.

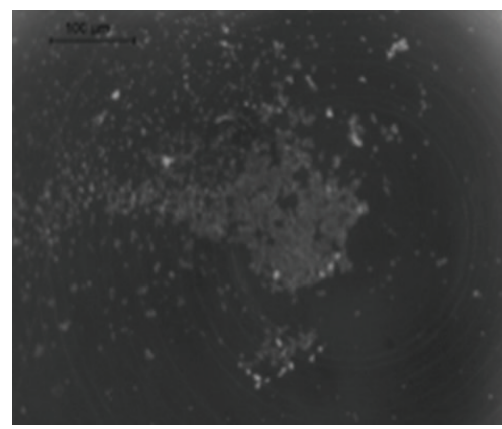

(a)

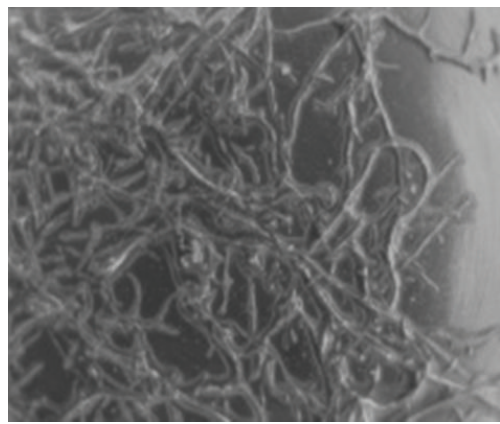

(d)

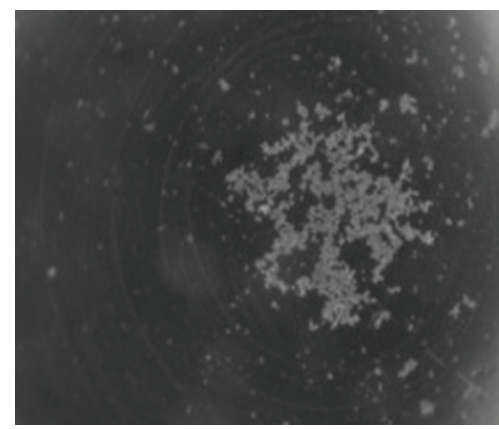

(b)

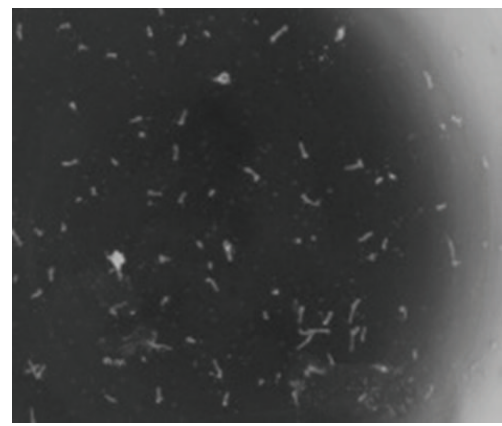

(e)

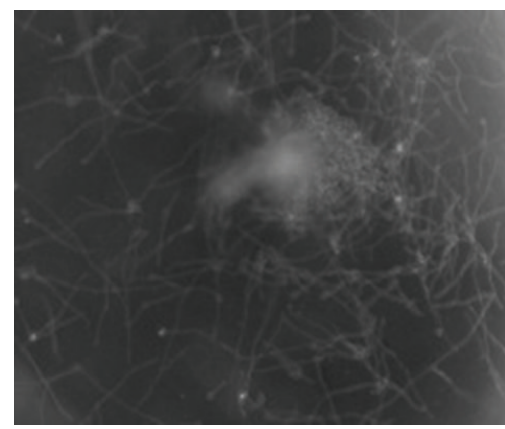

(c)

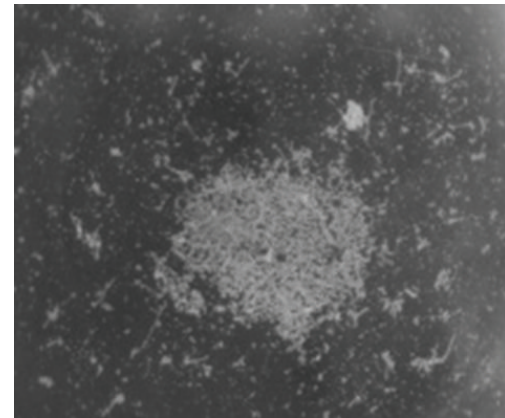

(f)

Figure 4: Aspergillus sp. 1 (a), Aspergillus sp. 2 (b), Botrytis sp. (c), Alternaria sp. (d), Cladosporium sp. (e), and Penicillium sp. (f) after 24 h in water. 


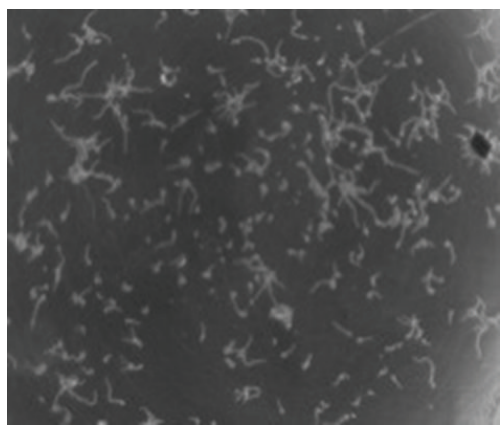

(a)

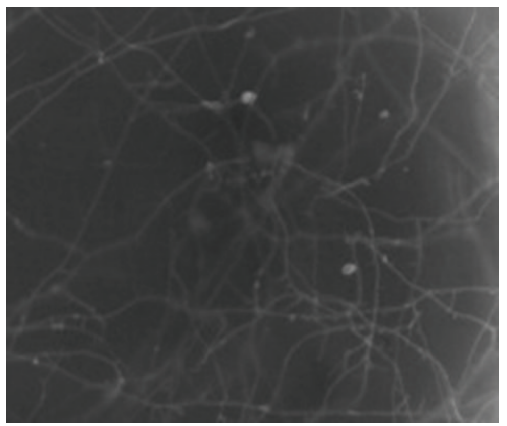

(d)

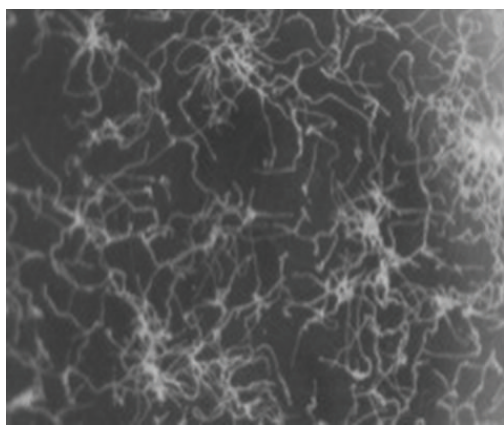

(b)

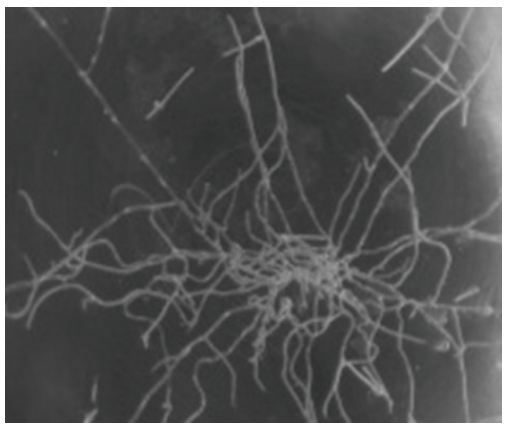

(e)

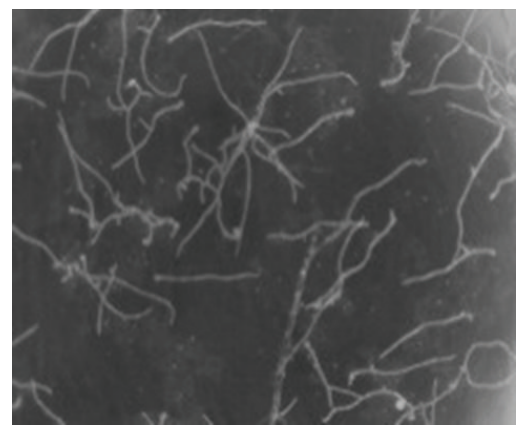

(c)

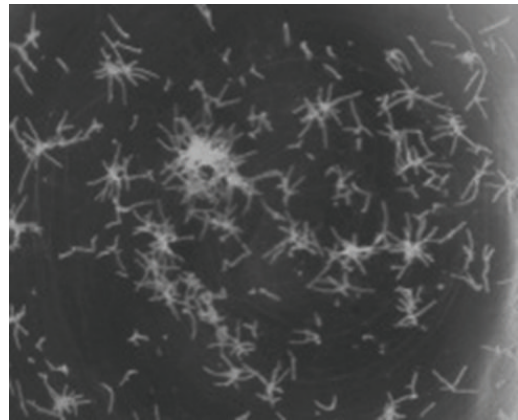

(f)

Figure 5: Aspergillus sp. 1 (a), Aspergillus sp. 2 (b), Botrytis sp. (c), Alternaria sp. (d), Cladosporium sp. (e), and Penicillium sp. (f) after 8 h in R2A Broth.

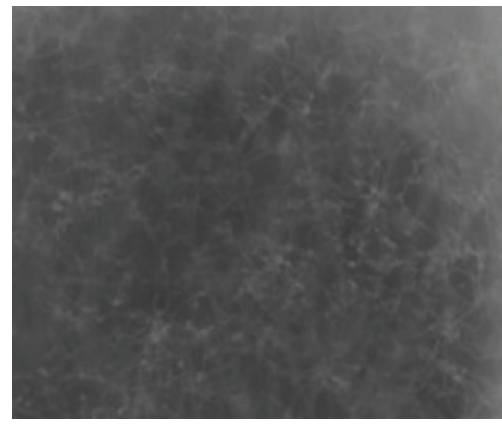

(a)

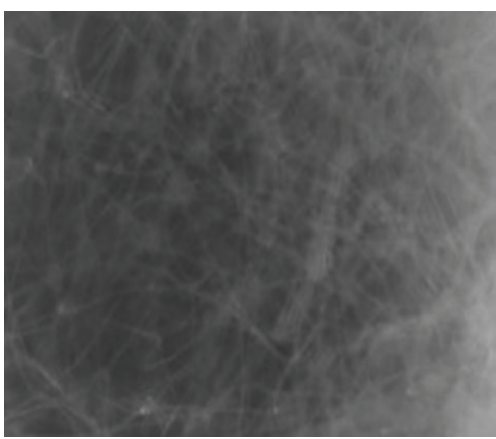

(d)

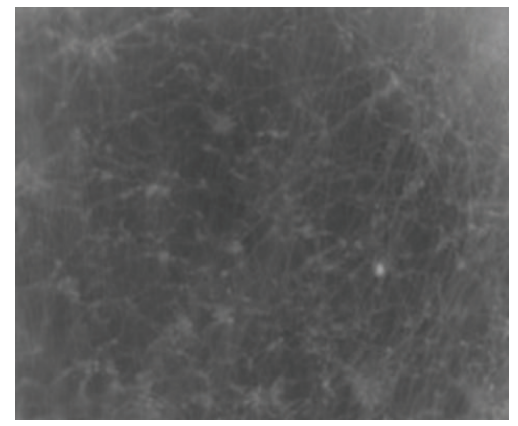

(b)

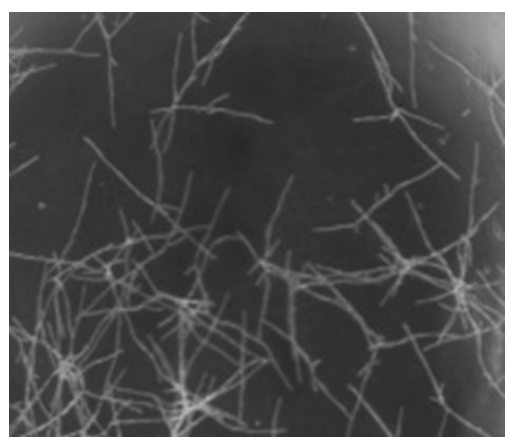

(e)

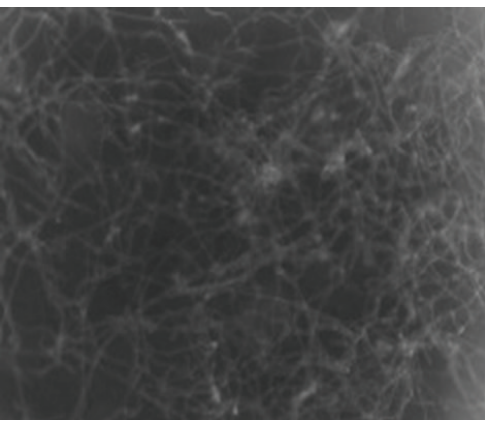

(c)

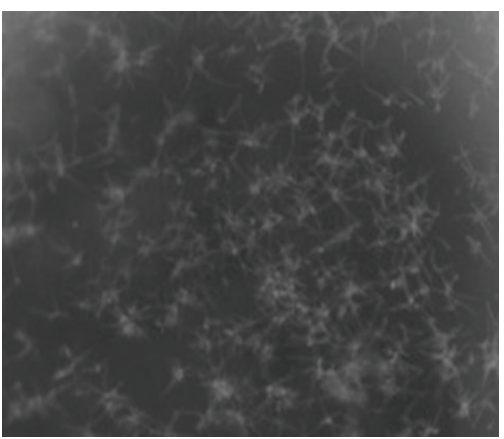

(f)

Figure 6: Aspergillus sp. 1 (a), Aspergillus sp. 2 (b), Botrytis sp. (c), Alternaria sp. (d), Cladosporium sp. (e), and Penicillium sp. (f) after 24 h in R2A Broth. 


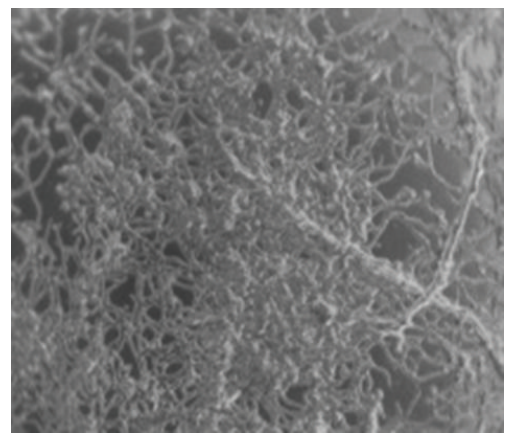

(a)

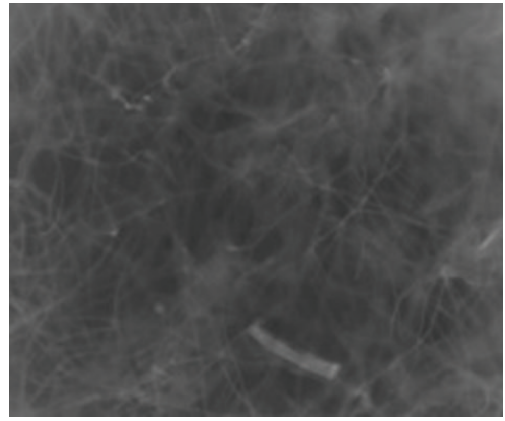

(d)

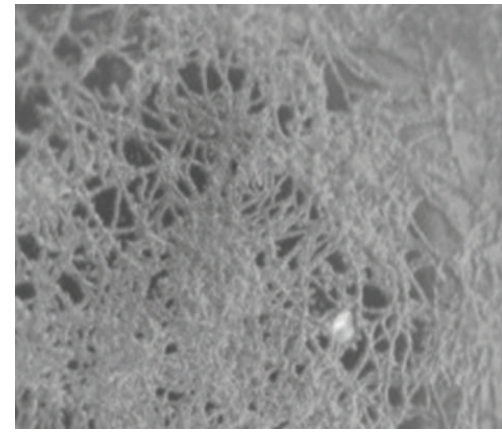

(b)

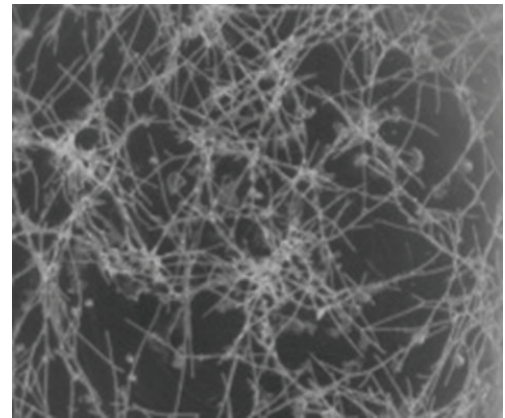

(e)

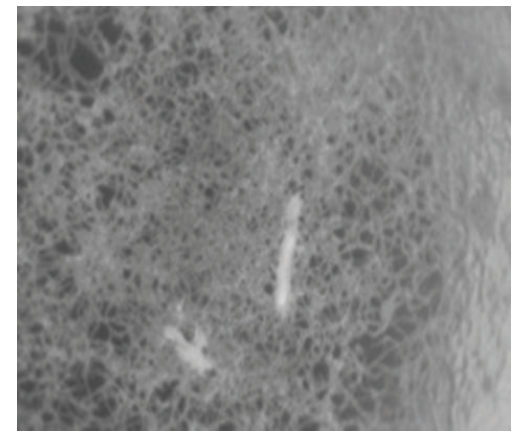

(c)

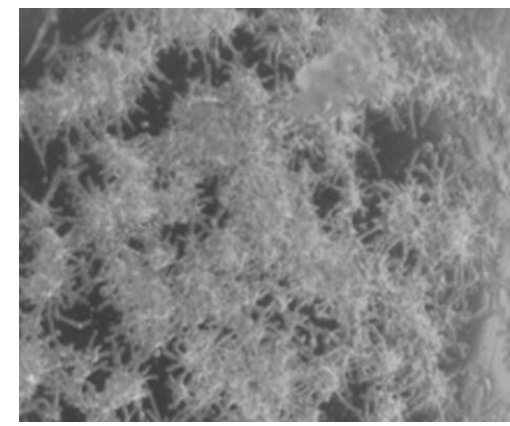

(f)

Figure 7: Aspergillus sp. 1 (a), Aspergillus sp. 2 (b), Botrytis sp. (c), Alternaria sp. (d), Cladosporium sp. (e), and Penicillium sp. (f) after 8 h in MEB.

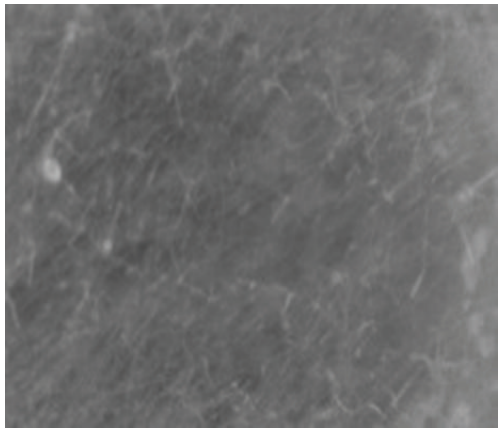

(a)

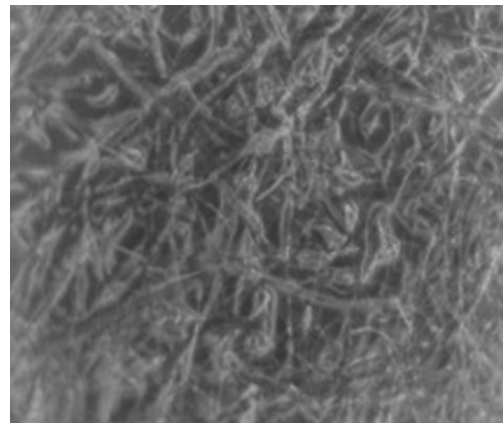

(d)

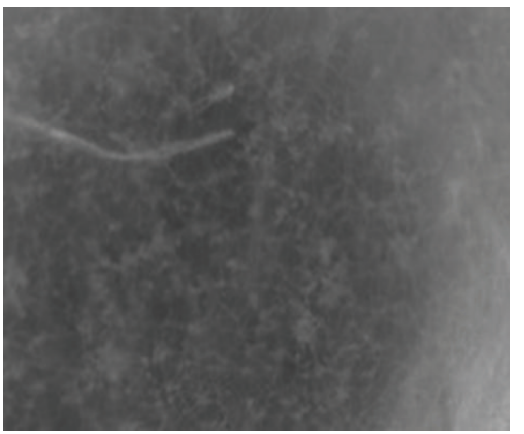

(b)

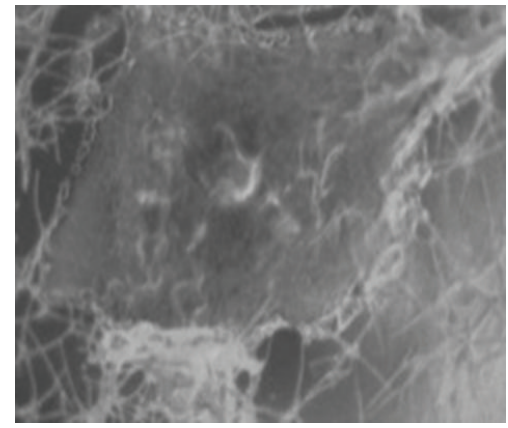

(e)

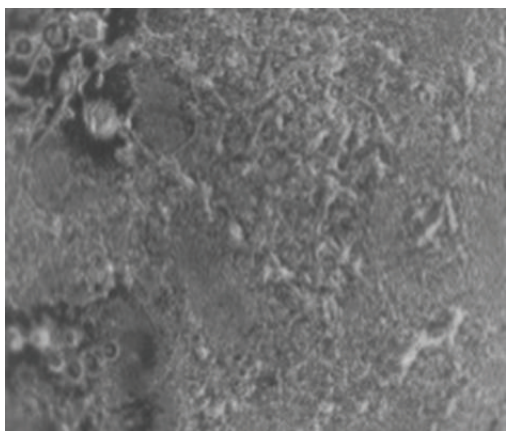

(c)

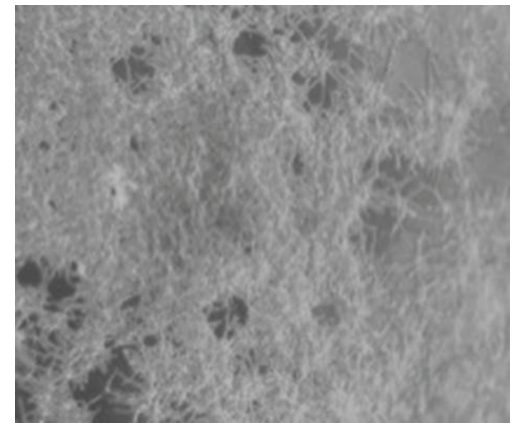

(f)

Figure 8: Aspergillus sp. 1 (a), Aspergillus sp. 2 (b), Botrytis sp. (c), Alternaria sp. (d), Cladosporium sp. (e), and Penicillium sp. (f) after 24 h in MEB. 
allergic responses in susceptible individuals exposed to contaminated water of shower, bath, and saunas or even to waterdamaged buildings [35].

In previous studies, the spore density in the initial spore suspension was verified as a key factor in the development of biofilms by ff [24]. Singh et al. [13] found that for Rhizopus oryzae, Lichtheimia corymbifera, and Rhizomucor pusillus, the initial inoculum plays a key role in germination of the adhered spores as well as structural integrity of the biofilms formed, a phenomenon also described in studies in Aspergillus niger [34] and A. fumigatus biofilms [17].

Bonaventura et al. [36] selected an inoculum size of $10^{5}$ $\mathrm{CFU} / \mathrm{mL}$, an adhesion time of $1 \mathrm{~h}$, and a biofilm formation time of $72 \mathrm{~h}$ as optimal experimental conditions for growing Trichosporon asahii biofilm on polystyrene surfaces. Our findings showed that time for spore adherence and further biofilm development varied for each fungus under different culture conditions. Nonetheless, spore characteristics such as size and surface proprieties may also influence biofilm kinetics.

Airborne fungal spores have a hydrophobic surface which aids dispersal, prevents desiccation, and may provide a barrier to the entry of toxicants [37]. Studies report that fungal spore hydrophobicity influences their capacity to adhere to biological surfaces, and that spore hydrophobicity is significantly influenced by culture conditions [38]. Fungal cultures in culture media which have high nutrient content are likely to produce more hydrophobic spores; the opposite is found when culture media with low nutrient content are used [39]. As spore hydrophobicity may interfere in spore adhesion and consequently in biofilm formation, attention must be paid on previous culture conditions. Siqueira and Lima [40] found that water biofilms of Penicillium spp. have specific hydrophobic hyphae which may be involved in fungal ecological functions. The different levels of hydrophobicity within a biofilm may also interfere in biofilm development and morphology, and consequently when different methods are applied they may significantly interfere in fungal biofilms characteristics. Thus, methods in ff biofilm characterization need urgently to be standardized.

The colorimetric method using the dye MTT has been cogitated as an alternative to traditional methods for in vitro susceptibility testing of fungi [41] and has been applied in fungal biofilms $[42,43]$. In this work, MTT values did not correlate with biofilm biomass assessed by $\mathrm{CV}$, mainly in older biofilms, that is, $24 \mathrm{~h}$ aged. Older biofilms showed a higher EPS production, which may interfere in the assessment of MTT to cell. Freimoser et al. [44] demonstrated that MTT method serves as a measure for cell densities of the entomopathogenic fungi Neozygites parvispora and Entomophthora thripidum and emphasized that for these two fungi the incubation period had to be longer (i.e., $16 \mathrm{~h}$ ) because the cell wall might act as an additional barrier for the uptake of MTT. Thus, MTT may not be the best method to evaluate cell viability in mature biofilms.

In conclusion, the results presented here show that the ff studied in this work are able to form biofilms under the applied conditions. Although each fungus presented a different pattern of biofilm development, spore adhesion, monolayer, and EPS production were observed in all fungal species over $24 \mathrm{~h}$ of analyses. Moreover, characteristics of spores and culture conditions may play an important role in ff biofilm kinetics and must be taken into consideration for further studies in this area.

\section{References}

[1] C. M. Wurzbacher, F. Bärlocher, and H. P. Grossart, "Fungi in lake ecosystems," Aquatic Microbial Ecology, vol. 59, no. 2, pp. 125-149, 2010.

[2] U. Szewzyk, R. Szewzyk, W. Manz, and K. H. Schleifer, "Microbiogical safety of drinking water," Annual Review of Microbiology, vol. 54, pp. 81-127, 2000.

[3] J. W. Costerton, K. J. Cheng, G. G. Geesey et al., "Bacterial biofilms in nature and disease," Annual Review of Microbiology, vol. 41, pp. 435-464, 1987.

[4] A. B. Gonçalves, I. M. Santos, R. R. M. Paterson, and N. Lima, "FISH and Calcofluor staining techniques to detect in situ filamentous fungal biofilms in water," Revista Iberoamericana de Micologia, vol. 23, no. 3, pp. 194-198, 2006.

[5] N. B. Sammon, K. M. Harrower, L. D. Fabbro, and R. H. Reed, "Three potential sources of microfungi in a treated municipal water supply system in sub-tropical Australia," International Journal of Environmental Research and Public Health, vol. 8, no. 3, pp. 713-732, 2011.

[6] V. M. Siqueira, H. M. B. Oliveira, C. Santos, R. R. M. Paterson, N. B. Gusmão, and N. Lima, "Filamentous fungi in drinking water, particularly in relation to biofilm formation," International Journal of Environmental Research and Public Health, vol. 8, no. 2, pp. 456-469, 2011.

[7] J. Chandra, D. M. Kuhn, P. K. Mukherjee, L. L. Hoyer, T. McCormick, and M. A. Ghannoum, "Biofilm formation by the fungal pathogen Candida albicans: development, architecture, and drug resistance," Journal of Bacteriology, vol. 183, no. 18, pp. 5385-5394, 2001.

[8] L. J. Douglas, "Candida biofilms and their role in infection," TRENDS in Microbiology, vol. 11, pp. 30-36, 2003.

[9] D. W. Williams, T. Kuriyama, S. Silva, S. Malic, and M. A. O. Lewis, "Candida biofilms and oral candidosis: treatment and prevention,” Periodontology, vol. 55, no. 1, pp. 250-265, 2011.

[10] E. Mowat, C. Williams, B. Jones, S. McChlery, and G. Ramage, "The characteristics of Aspergillus fumigatus mycetoma development: is this a biofilm?" Medical Mycology, vol. 47, no. 1, pp. S120-S126, 2009.

[11] S. Bruns, M. Seidler, D. Albrecht et al., "Functional genomic profiling of Aspergillus fumigatus biofilm reveals enhanced production of the mycotoxin gliotoxin," Proteomics, vol. 10, no. 17, pp. 3097-3107, 2010.

[12] F. M. C. Müller, M. Seidler, and A. Beauvais, "Aspergillus fumigatus biofilms in the clinical setting," Medical Mycology, vol. 49, no. 1, pp. S96-S100, 2011.

[13] R. Singh, M. R. Shivaprakash, and A. Chakrabarti, "Biofilm formation by zygomycetes: quantification, structure and matrix composition," Microbiology Papers, vol. 157, no. 9, pp. 2611-2618, 2011.

[14] D. M. Kuhn, T. George, J. Chandra, P. K. Mukherjee, and M. A. Ghannoum, "Antifungal susceptibility of Candida biofilms: unique efficacy of amphotericin B lipid formulations and echinocandins," Antimicrobial Agents and Chemotherapy, vol. 46, no. 6, pp. 1773-1780, 2002. 
[15] M. M. Harriott and M. C. Noverr, "Candida albicans and Staphylococcus aureus form polymicrobial biofilms: effects on antimicrobial resistance," Antimicrobial Agents and Chemotherapy, vol. 53, no. 9, pp. 3914-3922, 2009.

[16] S. Silva, M. Henriques, R. Oliveira, D. Williams, and J. Azeredo, "In vitro biofilm activity of non-Candida albicansCandida species," Current Microbiology, vol. 61, no. 6, pp. 534-540, 2010.

[17] G. Ramage, R. Rajendran, M. Gutierrez-Correa, B. Jones, and C. Williams, "Aspergillus biofilms: clinical and industrial significance," FEMS Microbiology Letters, vol. 324, no. 2, pp. 89-97, 2011.

[18] A. A. Gorbushina, "Life on the rocks," Environmental Microbiology, vol. 9, pp. 1613-1631, 2007.

[19] R. B. Srivastava, M. Awasthi, M. C. Upreti, and G. N. Mathur, "Studies on Aureobasidium pullulans forming biofilm on high strength aluminium alloy, a structural component, in aircraft fuel tanks," Indian Journal of Engineering and Materials Sciences, vol. 13, no. 2, pp. 135-139, 2006.

[20] A. A. Gorbushina, J. Heyrman, T. Dornieden et al., "Bacterial and fungal diversity and biodeterioration problems in mural painting environments of St. Martins church (Greene-Kreiensen, Germany)," International Biodeterioration and Biodegradation, vol. 53, no. 1, pp. 13-24, 2004.

[21] M. L. Grbić, J. Vukojević, G. S. Simić, J. Krizmanić, and M. Stupar, "Biofilm forming cyanobacteria, algae and fungi on two historic monuments in Belgrade, Serbia," Archives of Biological Sciences, vol. 62, no. 3, pp. 625-631, 2010.

[22] W. Lan, H. Li, W. D. Wang, Y. Katayama, and J. D. Gu, "Microbial community analysis of fresh and old microbial biofilms on Bayon Temple sandstone of Angkor Thom, Cambodia," Microbial Ecology, vol. 60, no. 1, pp. 105-115, 2010.

[23] B. J. Baker, G. W. Tyson, L. Goosherst, and J. F. Banfield, "Insights into the diversity of eukaryotes in acid mine drainage biofilm communities," Applied and Environmental Microbiology, vol. 75, no. 7, pp. 2192-2199, 2009.

[24] E. Mowat, J. Butcher, S. Lang, C. Williams, and G. Ramage, "Development of a simple model for studying the effects of antifungal agents on multicellular communities of Aspergillus fumigatus," Journal of Medical Microbiology, vol. 56, no. 9, pp. 1205-1212, 2007.

[25] V. M. Siqueira, Study of filamentous fungal biofilms with molecular and microscopic techniques [Ph.D. dissertation in Chemical and Biological Engineering], 2011, http://hdl.handle.net/1822/ 19679.

[26] C. G. Pierce, P. Uppuluri, A. R. Tristan et al., "A simple and reproducible 96-well plate-based method for the formation of fungal biofilms and its application to antifungal susceptibility testing," Nature Protocols, vol. 3, no. 9, pp. 1494-1500, 2008.

[27] A. Beauvais, C. Schmidt, S. Guadagnini et al., "An extracellular matrix glues together the aerial-grown hyphae of Aspergillus fumigatus," Cellular Microbiology, vol. 9, no. 6, pp. 1588-1600, 2007.

[28] M. W. Harding, L. L. R. Marques, R. J. Howard, and M. E. Olson, "Can filamentous fungi form biofilms?" Trends in Microbiology, vol. 17, no. 11, pp. 475-480, 2009.

[29] J. I. Prosser, "Hyphal growth patterns," in Fungal Differentiation: A contemporary Synthesis, J. E. Smith, Ed., pp. 357-396, MarcelDekker, New York, NY, USA, 1983.

[30] M. Gutiérrez-Correa, Y. Ludeña, G. Ramage, and G. K. Villena, "Recent advances on filamentous fungal biofilms for industrial uses," Applied Biochemistry and Biotechnology, vol. 167, pp. 12351253, 2012.
[31] P. Stoodley, K. Sauer, D. G. Davies, and J. W. Costerton, "Biofilms as complex differentiated communities," Annual Review of Microbiology, vol. 56, pp. 187-209, 2002.

[32] D. G. Allison, “The biofilm matrix," Biofouling, vol. 19, pp. 139150, 2003.

[33] G. K. Villena, T. Fujikawa, S. Tsuyumu, and M. GutiérrezCorrea, "Structural analysis of biofilms and pellets of Aspergillus niger by confocal laser scanning microscopy and cryo scanning electron microscopy," Bioresource Technology, vol. 101, no. 6, pp. 1920-1926, 2010.

[34] G. K. Villena and M. Gutiérrez-Correa, "Production of cellulase by Aspergillus niger biofilms developed on polyester cloth," Letters in Applied Microbiology, vol. 43, no. 3, pp. 262-268, 2006.

[35] J. U. Ponikau, "The diagnosis and incidence of allergic fungal sinusitis," Mayo Clinic Proceedings, vol. 74, no. 9, pp. 877-884, 1999.

[36] G. Di Bonaventura, A. Pompilio, C. Picciani, M. Iezzi, D. D'Antonio, and R. Piccolomini, "Biofilm formation by the emerging fungal pathogen Trichosporon asahii: development, architecture, and antifungal resistance," Antimicrobial Agents and Chemotherapy, vol. 50, no. 10, pp. 3269-3276, 2006.

[37] J. L. Laseter, J. Weete, and D. J. Weber, "Alkanes, fatty acid methyl esters, and free fatty acids in surface wax of Ustilago maydis," Phytochemistry, vol. 7, no. 7, pp. 1177-1181, 1968.

[38] T. Singh, R. Saikia, T. Jana, and D. K. Arora, "Hydrophobicity and surface electrostatic charge of conidia of the mycoparasitic Trichoderma species," Mycological Progress, vol. 3, pp. 219-228, 2004.

[39] D. J. Holder, B. H. Kirkland, M. W. Lewis, and N. O. Keyhani, "Surface characteristics of the entomopathogenic fungus Beauveria (Cordyceps) bassiana," Microbiology, vol. 153, no. 10, pp. 3448-3457, 2007.

[40] V. M. Siqueira and N. Lima, "Surface hydrophobicity of culture and water biofilm of Penicillium spp," Current Microbiology, vol. 64, pp. 93-99, 2012.

[41] J. Meletiadis, J. F. G. M. Meis, J. W. Mouton, J. P. Donnelly, and P. E. Verweij, "Comparison of NCCLS and 3-(4,5-dimethyl2-thiazyl)-2,5-diphenyl-2H-tetrazolium bromide (MTT) methods of in vitro susceptibility testing of filamentous fungi and development of a new simplified method," Journal of Clinical Microbiology, vol. 38, no. 8, pp. 2949-2954, 2000.

[42] B. Jahn, A. Stüben, and S. Bhakdi, "Colorimetric susceptibility testing for Aspergillus fumigatus: comparison of menadione-augmented 3-(4,5-dimethyl-2-thiazolyl)-2,5-diphenyl2H-tetrazolium bromide and Alamar Blue tests," Journal of Clinical Microbiology, vol. 34, no. 8, pp. 2039-2041, 1996.

[43] B. P. Krom, J. B. Cohen, G. E. McElhaney Feser, and R. L. Cihlar, "Optimized candidal biofilm microtiter assay," Journal of Microbiological Methods, vol. 68, no. 2, pp. 421-423, 2007.

[44] F. M. Freimoser, C. A. Jakob, M. Aebi, and U. Tuor, "The MTT [3(4,5-dimethylthiazol-2-yl)-2,5-diphenyltetrazolium bromide] assay is a fast and reliable method for colorimetric determination of fungal cell densities," Applied and Environmental Microbiology, vol. 65, no. 8, pp. 3727-3729, 1999. 

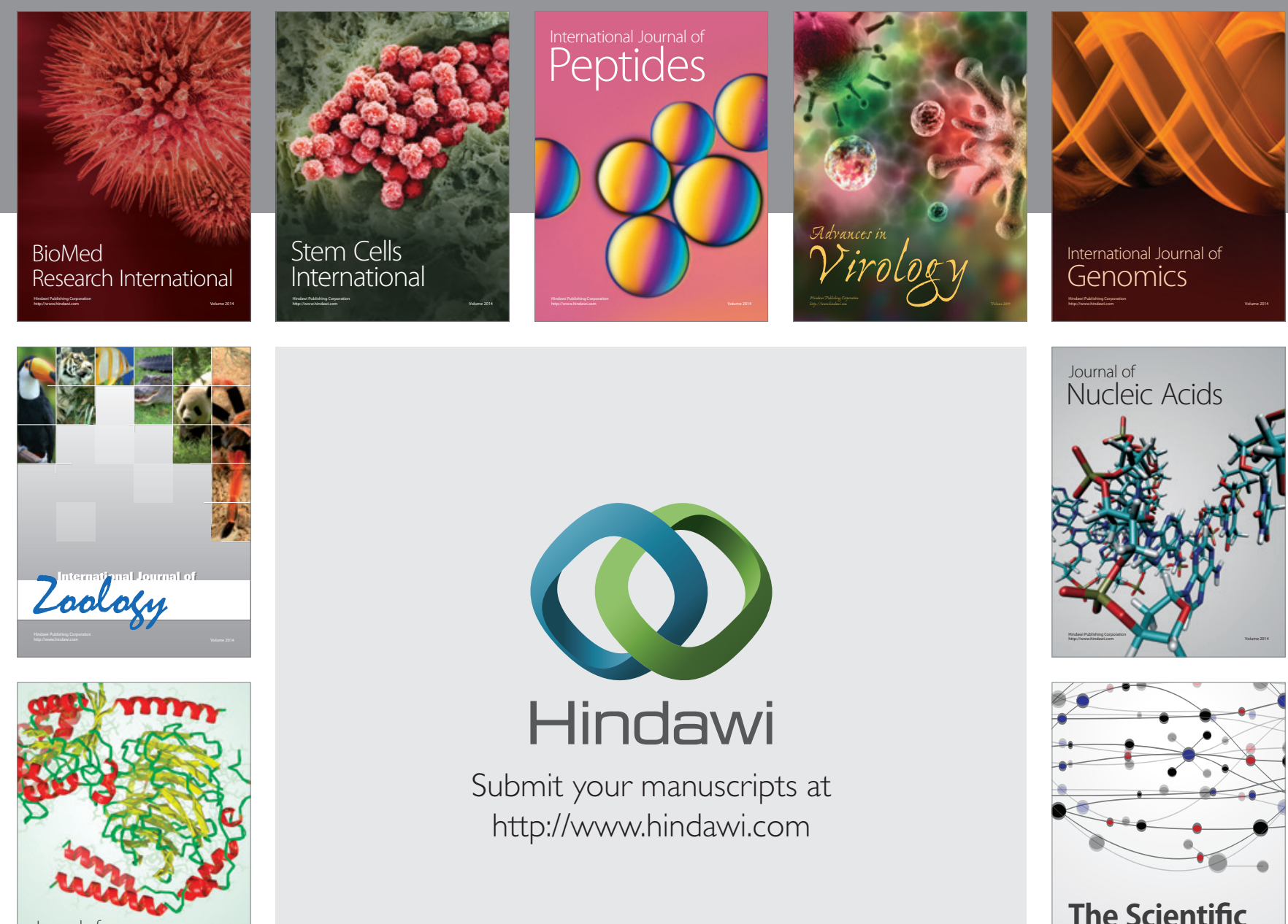

Submit your manuscripts at

http://www.hindawi.com

Journal of
Signal Transduction
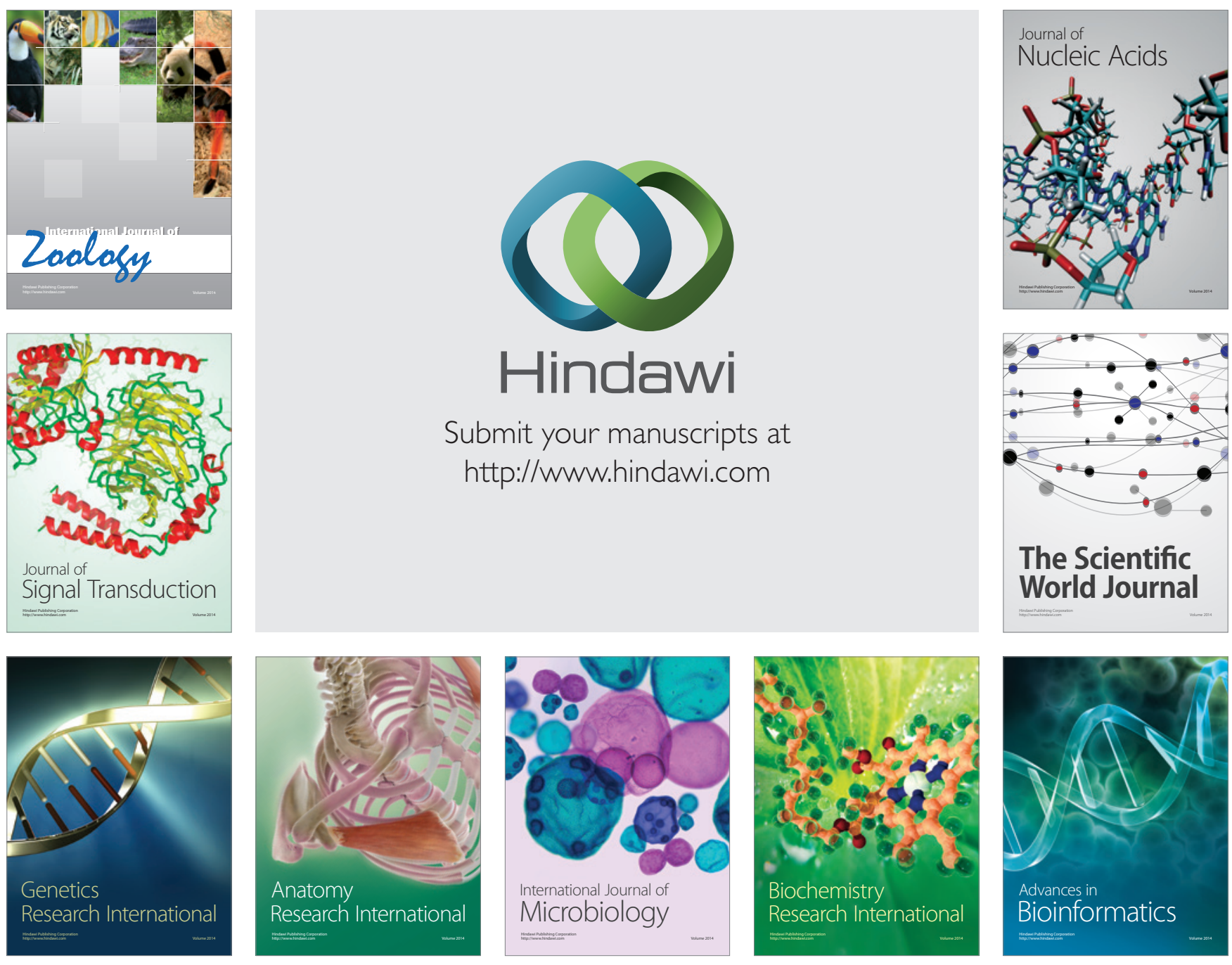

The Scientific World Journal
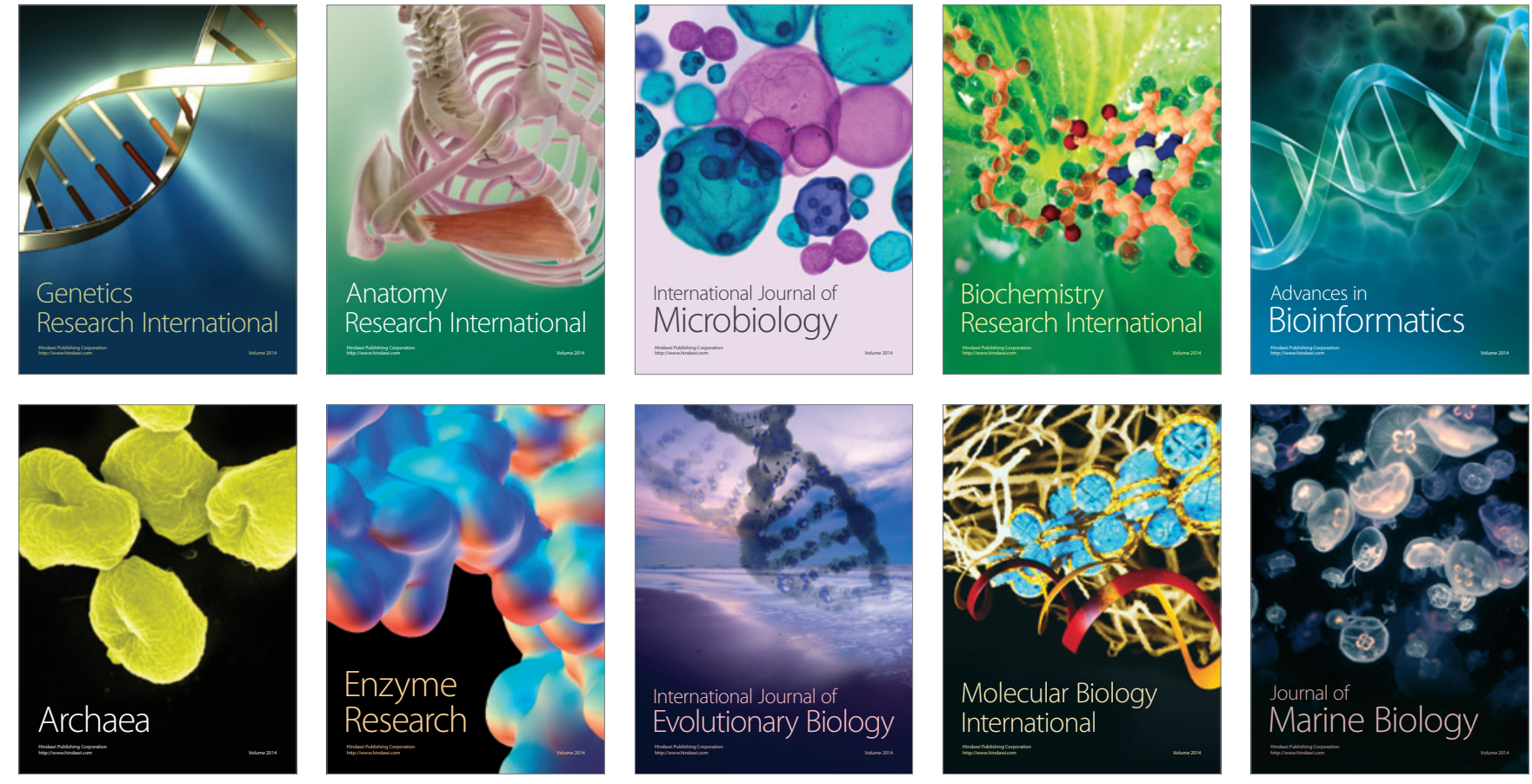